\title{
13 EMERGENCY PROBLEMS IN OLDER PEOPLE
}

Emerg Med J 2005;22:370-374. doi: 10.1136/emj.2005.023770

M edical emergencies are common in older people. They may have difficulty accessing suitable health care once their GP practice is closed. They are less likely to use schemes such as NHS Direct than other parts of the population. ${ }^{1}$ They or their carers are more likely to dial 999 if they have an urgent medical problem. The care of the elderly is an increasing proportion of work for GP out of hours services, ambulance services, and Emergency Departments (EDs).

The acute medical problems of older people are often similar to those of younger adults but the presentation can be atypical or there can be a number of co-existing problems that make diagnosis difficult. Further difficulties occur in frailer, older adults who continue to manage at home despite the effects of increasing age and multiple medical problems. In these patients an apparently minor illness can lead to deterioration in a non-specific manner leading to immobility, a fall, or acute confusion. The social circumstances and the availability of social support may be of greater importance than the management of the medical illness. Treatment at home is often the preferred and safest option. If a careful clinical and social assessment indicate that the primary problems require social support or nursing expertise, then clinicians must have the option of referring to community support schemes that are now more widely available.

However, major illnesses such as serious infections, heart disease, and cancer can also present in a non-specific way. If the presence of one of these conditions is a possibility, then a planned short admission for investigation or early clinic review will be preferable to leaving the patient at home with subsequent admission in a worse condition at a later time.

The management of trauma and surgical emergencies is covered in other articles in this series. Discussion of single organ emergency problems in older adults such as myocardial infarction will be brief because they should be dealt with in a very similar way to their management in younger adults.

The main emphasis of this chapter is the assessment of physical state, mental state, medication, and social circumstances in older adults presenting in a less specific manner such as with general deterioration, falls, confusion, and minor injuries.

\section{COMMUNITY SYSTEMS FOR THE CARE OF OLDER PEOPLE}

The proper care of the older patient is one of the major priorities of many health systems. Some "full systems approaches" are emerging but often they lack co-ordination and might only be available for limited times of the week. The bedrock of community care is Primary Care. In the future this will be augmented with support from GPs with a special interest in care of the elderly or community care of the elderly specialists ("community geriatricians") or intensive case management nurses. However, acute events are common in this group and there needs to be a coordinated system to respond to emergency calls for help.

Figure 1 sets out the range of outcomes from community emergency assessment and shows the ideal system to respond to these emergencies. The community emergency medicine clinician carries out initial crisis support and a brief needs assessment. In significant numbers of older patients this will need to be backed up by either hospital or community services. The keys to success in such a system are excellent communication, mutual respect, and clear referral pathways with common documentation systems.

See end of article for authors' affiliations

Correspondence to: P Lawson, Brearley Wing, Northern General Hospital Herries Road, Sheffield, S5

7AU, UK; peter.lawson@ sth.nhs.uk

\section{PRIMARY SURVEY POSITIVE PATIENTS}

The criteria for recognition of immediately life threatening problems are the same as for younger patients (Box 1). However, the interpretation of vital signs may be more difficult and abnormalities need to be taken in context of pre-existing morbidity. A history from a reliable witness is essential. Previous neurological problems can make the GCS permanently less than 12. Similarly, the elderly are more prone to excessive bradycardia from cardiac medication but on the other hand, symptomatic heart block is common. Oxygen saturations should be interpreted in light of the known medical history and clinical setting. 


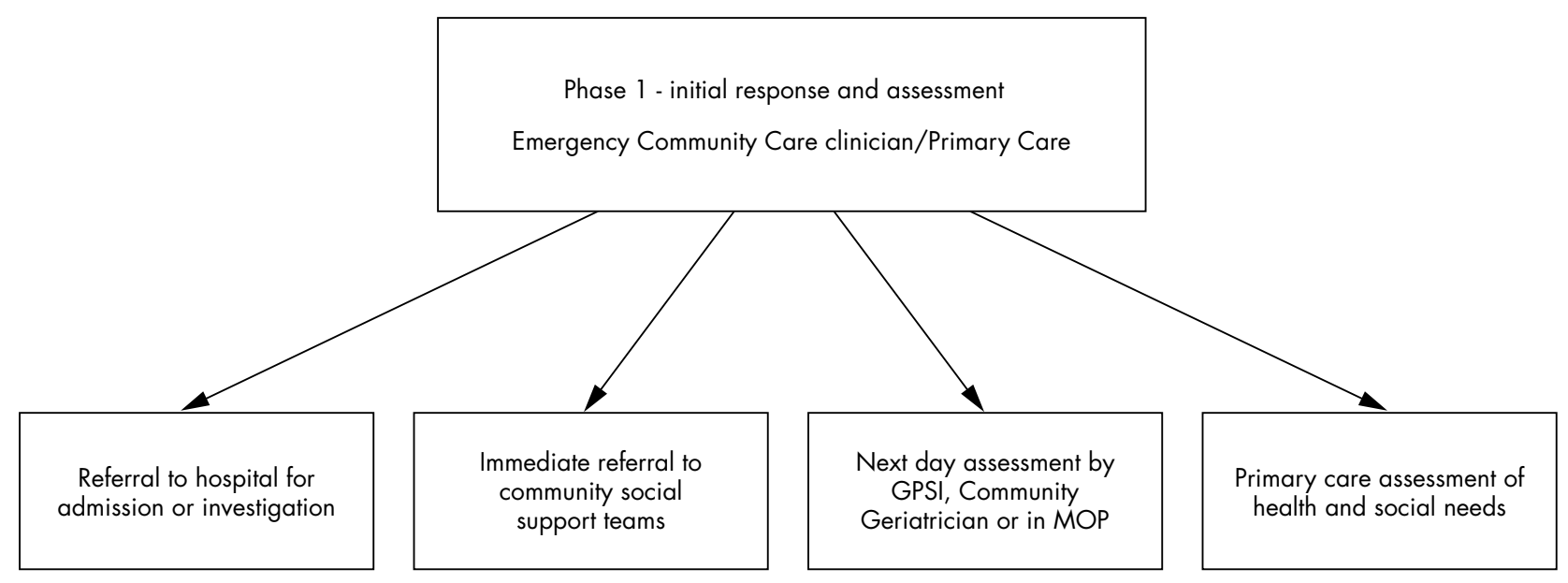

A model of the system for dealing with emergencies that are not immediately like threatening in the older patient.

Primary survey positive patients should be transferred as soon as possible by paramedic ambulance to an A\&E Department or an Emergency Admissions Unit depending on local protocols. The exception might be those patients with documented "end of life decisions" such as advanced directives and clear, agreed treatment plans, which might include "do not attempt resuscitation" (DNAR) orders.

More than any other group of patients, the older adult might refuse transfer to hospital. If gentle coaxing has failed, carers and family can often be more persuasive. Sometimes it is necessary to consider whether the patient has the mental capacity to refuse transfer for assessment and treatment. In this situation it is possible to agree with family and carers that it is in the patient's best interests to be taken to hospital, especially if they are suffering from serious life threatening illness. Clear documentation of such decisions is essential in this situation.

\section{Box 1 -Vital signs indicating "primary survey} positive patient"

- A-potential airway compromise

- unconscious patient / stridor / anaphylaxis / Hx of foreign body

- B-severe distress

respiratory rate $<10$ or $>29$

oxygen sats $<93 \%$ on air with no history of COPD

- C-clinical signs of shock

- pulse $<50$ or $>120$

systolic BP $<90 \mathrm{mmHg}$

- D-GCS $<12$ (acute deterioration)

- (acute stroke)

\section{PRIMARY SURVEY NEGATIVE PATIENTS}

In the elderly patient a greater emphasis must be given to factors other than the "medical problem" alone. The variables to be considered include severity of the medical problem, cognitive status of the patient, social circumstances of the patient, and the availability of health and social care services.

Abbreviations: DNAR, do not attempt resuscitation; ECG, electrocardiograph; ED, Emergency Deparment
Box 2-Factors to consider when planning the management of acute events in older people

- Severity of medical problem

- Cognitive status of the patient

- Social circumstances

- Availability of community health and social care support.

\section{Severity of the medical problem}

Patients with signs or symptoms of severe illness should be transferred to hospital unless there are exceptional circumstances. Even with less severe presenting complaints, review in hospital might still be necessary for medical reasons. The elderly are less able to withstand blood loss following, for example, epistaxis or a laceration. They may have a myocardial infarction despite presenting with only minor or no chest pain. There may be only limited signs of peritonism despite significant intra-abdominal pathology. They are at higher risk of developing intracranial haemorrhage and neuropsychological sequelae following a minor head injury. It is best to be cautious and where there is suspicion of serious pathology the patient should be sent to hospital for medical assessment or arrangements made for an immediate visit by the patient's GP.

\section{Cognitive status of the patient}

The presence of cognitive impairment often renders the history and self-reported ability with activities of daily living unreliable. It is important for any community practitioner to be able to recognise cognitive impairment and, where possible, confirm history with a reliable witness. Impaired cognition in someone living alone might mean they are unable to look after themselves despite an illness being only minor.

\section{Social circumstances}

When the medical condition does not of itself indicate that hospital admission is required, the patient's social circumstances may have a large bearing on whether they can remain at home. The availability of someone to provide food and hydration, give medication, and call for help if their condition deteriorates is crucial for a person who has had a fall with soft tissue injury, has a chest infection, or a minor head injury. If the patient is living alone, explore other sources of 
help such as family or friends. If such help is not available then it might be necessary to arrange emergency support from community rapid response teams.

A further complication is that the patient may be the main carer for someone else. If this is the case, social services should be contacted to arrange a sitting service or temporary respite placement until the carer is able to resume those duties. Thus, a review of social circumstances includes finding out if the patient has someone who could act as a carer or if they provide care for someone themselves.

\section{堬 Tip}

The patient may be the main carer for a partner or spouse, if they are admitted to hospital you may need to arrange care for the other person.

\section{Health and Social Care Services}

Across the UK there are a range of services under a variety of names with the primary purpose of supporting older patients at home or within supported settings outside hospital. Knowledge of the locally available services and how to contact them is crucial. Most services provided at home include care workers, nurses, and therapists. A relatively new concept is that of "intensive case management". Patients with high medical, nursing or social needs may have specialist teams already assigned to their care.

\section{NON-SPECIFIC PRESENTATIONS OF ILLNESS IN OLDER PATIENTS}

Patients presenting with non specific complaints make up a large proportion of most hospitals' acute medical admissions. The presentation can be with confusion, falls, being "off legs", or with the label of being "a social admission".

These "non-specific" presentations are common and create significant diagnostic and management problems but a seemingly minor injury or illness can be due to several underlying medical conditions. Many of the underlying causes of these different presentations are similar and it is perhaps the relative mental or physical frailty of the person which determines how they present. Some of these causes are briefly given in Box 3 but fuller details are available in many textbooks. ${ }^{2}$

\section{Box 3-A brief summary of causes of falls and} acute confusion

- Medications, e.g. sedatives, hypotensive agents

- Infection, e.g. chest and urinary tract

- Metabolic disturbance, e.g. dehydration, alcohol, low sodium, or low glucose

- Neurological event or conditions, e.g. TIA, seizure

- Cardiovascular event or conditions, e.g. causing low cerebral perfusion

- Environmental causes, e.g. unfamiliar surroundings

The rest of this chapter will address the management of these patients by emergency community care clinicians or GPs. This will include taking a history, performing a focussed
Table 1 Assessment of vital signs and general appearance

\begin{tabular}{ll}
\hline Vital signs & $\begin{array}{l}\text { Pulse, blood pressure, respiratory } \\
\text { rate, oxygen saturations, temperature, } \\
\text { and GCS } \\
\text { General } \\
\text { Does the patient appear unwell? } \\
\text { Colour, rash, sweating, } \\
\text { Hydration, eyes, mouth }\end{array}$ \\
\hline
\end{tabular}

physical and mental status examination and formulating a management plan.

\section{SUBJECTIVE INFORMATION-HISTORY}

Not all patients in this age group are able to give a reliable history and thus it is essential to glean as much information as possible from carers. Details of general history taking are reviewed in chapter 2. Specific elements of the history, including the social history and features highlighted in Box 6, will determine the need for further investigation or transfer.

\section{OBJECTIVE INFORMATION- EXAMINATION}

Vital signs (table 1) are, as always, important but may be altered by pre-existing morbidity. The GCS is the most obvious example where pre-existing confusion will make assessment of the verbal score difficult. Similarly, pulse and blood pressure may be altered by pre-existing medications such as $\beta$ blockers. Any concern about the vital signs or general appearance of the patient should trigger an immediate hospital assessment.

The next stage is a focused systems examination. A full examination is required but given the huge number of problems causing falls or confusion certain areas should be given additional emphasis. The examination described in table 2 is aimed at patients with falls but most also applies to patients with confusion, including assessments of both physical and mental status.

There are many tools available for the assessment of cognitive function. Each has limitations but they can give an indication of problems with cognition and can be used to follow progress. Box 4 shows the 10 question Hodkinson Abbreviated Mental Test score, which combines brevity with

Table 2 Examination and simple tests for older patients with immobility, falls or acute confusion

\begin{tabular}{|c|c|}
\hline General appearance & $\begin{array}{l}\text { Evidence of not coping at home } \\
\text { Parkinsonian features eg rigidity, } \\
\text { tremor } \\
\text { Depression } \\
\text { Thyroid status } \\
\text { Flushed, pyrexial }\end{array}$ \\
\hline Cardiovascular & $\begin{array}{l}\text { Pulse including peripheral pulses } \\
\text { Lying and standing blood pressure } \\
\text { Source of emboli-heart rhythm, } \\
\text { murmurs, and bruits }\end{array}$ \\
\hline Neuromuscular system & $\begin{array}{l}\text { Lateralizing signs } \\
\text { Parkinson's disease } \\
\text { Proximal muscle weakness } \\
\text { Gait-Get up and Go test }{ }^{3}\end{array}$ \\
\hline $\begin{array}{l}\text { Abdomen } \\
\text { Infection }\end{array}$ & $\begin{array}{l}\text { Masses and constipation } \\
\text { Chest auscultation } \\
\text { Urine dipstick }\end{array}$ \\
\hline $\begin{array}{l}\text { Mental test score } \\
\text { Tests }\end{array}$ & $\begin{array}{l}\text { Hodkinson AMT }{ }^{4} \text { (see box } 4 \text { ) } \\
12 \text { lead ECG } \\
\text { BM stix } \\
\text { Urine dipstick }\end{array}$ \\
\hline
\end{tabular}


validity. Questions have to be asked in the order shown and are given one mark for the correct answer or no mark. A score below eight out of 10 implies cognitive impairment
GP must still be informed of the 'emergency' episode and they can then decide when to review the patient.

Examples of treat and leave patients include those with chronic balance and gait problems despite support from the falls service; those with an obvious minor infection suitable for treatment with oral antibiotics, or those with soft tissue injury but no bony tenderness and requiring only simple analgesia.

\section{TREAT AND REFER}

Many emergency calls reveal increased social care or community nursing needs. The occurrence of a previously un-investigated, non-specific presentation of illness in an older person also highlights the need for referral for a specialist assessment that can be started in Primary Care. Most health communities now have care pathways for dealing with patients presenting in a variety of ways - for example, following a fall. Those involved in emergency care must know how to access these pathways of care and how to obtain rapid response nursing and social care.

Another example suitable for treat and refer might be a patient who has fallen with a brief loss of consciousness or short period of palpitations. If they have recovered and have a normal 12 lead ECG they may be suitable to be left at home but referred for urgent review in a hospital or community clinic. An abnormal 12 lead ECG in the patient with loss of consciousness would, however, require hospital assessment.

Another reason for referral to hospital would be for xrays to exclude fracture. Referral pathways should be established to enable the community emergency practitioner to directly refer patients for an appropriate x-ray with varying urgency. $\mathrm{X}$-ray of what might be a minor fracture may be deferred if pain can be controlled with simple analgesics to avoid an admission in the middle of the night. However, if the patient is unable to care for themselves or the suspected fracture is associated with significant pain or neuro-vascular problems, an x-ray may be required in a shorter time-scale. Selfmobilising patients with suspected bony injuries to the upper limbs will rarely require transfer by emergency ambulance and alternative forms of transport should be considered.

\section{TREAT AND TRANSFER}

There are several groups of patients in this category. Some have worrying symptoms as in Box 5. Others are less ill but lack suitable support at home, or appropriate services to support the patient at home cannot be organised. If a bed in an Intermediate Care facility cannot be arranged, these patients will need to be taken to hospital. Finally, there are those who cannot be properly assessed at home and who need to be brought to the ED for this to be done.

When transfer is required, the community emergency practitioner can make an important contribution to the work of the ambulance service by recommending the most appropriate form of transport for patients requiring admission. For example, a patient requiring no care other than assistance to get to the vehicle will not require a paramedic staffed emergency ambulance, and can be safely cared for by staff with more limited training, thus preserving scarce resources for those patients most likely to benefit from them.

\section{OTHER FACTORS TO CONSIDER}

Any clinician seeing an older person in their home has the opportunity to assess the level of care that person is receiving and whether they are being subject to abuse. The pattern of further advice or help if their condition does not improve or deteriorates. If patients do not require further referral their 
Box 5-Worrying features making hospital

referral more likely

Falls

Recurrent blackouts

Altered behaviour before or after a fall

374 Associated symptoms, e.g. ischaemic chest pain requiring repeat ECG or cardiac enzymes, "dizziness" with a postural BP drop or with vertigo

New drowsiness

Inability to bear weight or use arms due to pain

Hip pain

\section{Confusion}

Acute onset

Recent medication changes

New symptoms such as personality change or focal weakness

Recent head injury

Behaviour likely to lead to harm for self or others

injury seen in physical abuse is often similar to those sustained during a fall but if the patient denies a fall the possibility of elder abuse should be considered. It should also be remembered that psychological, financial, and sexual abuse plus abuse through neglect can all lead to physical and mental decline resulting in an emergency assessment. If elder abuse is suspected, social services should be informed. Please visit www.elderabuse.org.uk for more information and advice.

\section{SUMMARY}

Practitioners dealing with emergencies in older adults in the community must be able to recognise the atypical presentation of illness in older people and have a high index of suspicion that apparently innocent symptoms can be the presentation of serious underlying pathology. It must also be remembered that the common medical emergencies of younger adults generally occur more frequently in older adults and require similar treatment.

Necessary skills include clear communication with patients although on occasions witnesses must be used to obtain relevant information. A focussed examination including a mental state test is often necessary when dealing with nonspecific illness in the older patient and when determining if someone can be left at home.

A home visit allows assessment of the patient's social circumstances and emergency practitioners might sometimes need to make adjustments to ensure the safety of the patient in their surroundings if they are to be left at home or subject to a delay in transfer. Evidence of neglect by the patient or by others should also be looked for when attending the patient at home. The combination of social and medical assessment, linked to knowledge of the services available locally will determine where the patient's care will be best delivered.

With an older patient it is safer to err on the side of caution to avoid denying patients a specialist assessment. For many this will need to be a comprehensive Geriatric assessment performed after the emergency episode has passed.

\section{Authors' affiliations}

P Lawson, Consultant Physician and Geriatrician, Northern General Hospital, Sheffield

C Richmond, Paramedic Practitioner, South Yorkshire Ambulance Service

\section{REFERENCES}

1 NHS Direct in England. Report by the Comptroller and Auditor General, National Audit Office. Published $25^{\text {th }}$ January 2002

2 Kenny RA. Falls and Syncope. Chapter 4.4 pages 111-124. Oxford Textbook of Geriatric Medicine. In: Grimley Evans J, Franklin Williams T, Lynne Beattie B, Michel J-P, Wilcock GK, eds. Pubs Oxford University Press, 2000.

3 Mathias S, Nayak US, Isaacs B. Balance in Elderly Patients: The "get-up and go" test. Arch phys Med Rehabil 1986;67:387-389.

4 Hodkinson HM. Evaluation of a mental test score for assessment of mental impairment in the elderly. Age and Ageing 1972;1:233-238. 